\title{
Metformin in cancer: translational challenges
}

\author{
Ryan J O Dowling ${ }^{1,2}$, Saroj Niraula ${ }^{2}$, Vuk Stambolic ${ }^{1,2}$ and Pamela J Goodwin ${ }^{3}$ \\ ${ }^{1}$ Division of Signalling Biology, Ontario Cancer Institute, University Health Network, Toronto, Ontario, Canada M5G 2M9 \\ ${ }^{2}$ Princess Margaret Hospital, 610 University Avenue, Toronto, Ontario, Canada M5G 2M9 \\ ${ }^{3}$ Division of Clinical Epidemiology, Department of Medicine, Samuel Lunenfeld Research Institute, Mount Sinai Hospital, \\ University of Toronto, 1284-600 University Avenue, Toronto, Ontario, Canada M5G 1X5 \\ (Correspondence should be addressed to P J Goodwin; Email: pgoodwin @mtsinai.on.ca)
}

\begin{abstract}
The anti-diabetic drug metformin is rapidly emerging as a potential anti-cancer agent. Metformin, effective in treating type 2 diabetes and the insulin resistance syndromes, improves insulin resistance by reducing hepatic gluconeogenesis and by enhancing glucose uptake by skeletal muscle. Epidemiological studies have consistently associated metformin use with decreased cancer incidence and cancer-related mortality. Furthermore, numerous preclinical and clinical studies have demonstrated anti-cancer effects of metformin, leading to an explosion of interest in evaluating this agent in human cancer. The effects of metformin on circulating insulin levels indicate a potential efficacy towards cancers associated with hyperinsulinaemia; however, metformin may also directly inhibit tumour growth. In this review, we describe the mechanism of action of metformin and summarise the epidemiological, clinical and preclinical evidence supporting a role for metformin in the treatment of cancer. In addition, the challenges associated with translating preclinical results into therapeutic benefit in the clinical setting will be discussed.
\end{abstract}

Journal of Molecular Endocrinology (2012) 48, R31-R43

\section{Introduction}

Emerging evidence from several areas of research suggests that metformin, a commonly used anti-diabetic drug, may be useful in the prevention and treatment of cancer. Metformin, a biguanide derivative, has been used for half a century to treat non-insulin-requiring diabetes. It is a relatively safe drug, with known pharmacokinetics and manageable toxicities. Its most common toxicity is mild-to-moderate gastrointestinal discomfort, usually self-limited and ameliorated by a graduated ramp up in dose. Its most serious toxicity, lactic acidosis, is rare (Bodmer et al. 2008), occurring once per 100000 years of use. Lactic acidosis is more common in elderly patients (over age 80 years) and in those with impaired renal, cardiac and/or hepatic function. Although metformin has only recently been directly tested in conjunction with anti-cancer agents in the clinical setting, its common use in the treatment of diabetes has resulted in its co-administration with virtually all anti-cancer agents in diabetic cancer patients. No evidence of important interactions of metformin with standard cancer therapies has emerged through this experience. Because of this, clinical evaluation of metformin as an anti-cancer agent has bypassed the traditional Phase I pharmacokinetic/ toxicity assessment and has moved directly into Phase II and Phase III testing, reflecting rapid accumulation of preclinical, clinical and epidemiological evidence that it may have beneficial anti-cancer effects, despite the fact that precise mechanisms of potential anti-cancer action remain unresolved (Goodwin et al. 2011).

Current understanding of potential anti-cancer effects of metformin raises the intriguing possibility of a duality of action - metformin may act directly on the tumour or it may act indirectly on the host by lowering insulin levels. This, along with the fact that the key host-related mediator (insulin) is a critical component of culture medium used in in vitro experiments, leads to enhanced challenges in translating results of preclinical research into the clinical setting, underscoring the importance of cross-disciplinary research approaches.

Here, we summarise emerging evidence from research on humans (epidemiological, clinical and metabolic) and from the preclinical setting (mechanistic, in vitro and in vivo research) suggesting that metformin has anticancer effects (Fig. 1). We then integrate this information to develop recommendations for translational evaluation of metformin in the clinical setting.

DOI: 10.1530/JME-12-0007

Online version via http://www.endocrinology-journals.org 


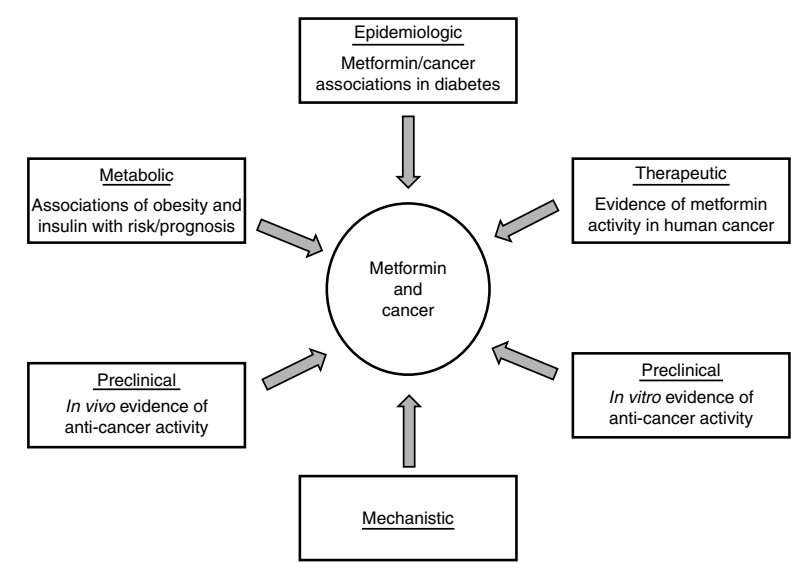

Figure 1 Evidence supporting the use of metformin in the treatment of cancer. The potential use of metformin in the prevention and treatment of cancer is based on emerging evidence from a number of research fields. Metabolic factors such as obesity and hyperinsulinaemia are associated with cancer risk while epidemiological studies have demonstrated a reduced incidence of cancer in diabetic patients receiving metformin. Moreover, preclinical studies have provided evidence of the anti-cancer effects of metformin and defined its mechanism of action.

\section{Research on humans}

\section{Epidemiologic}

Evans et al. (2005) were the first to report a potential association of metformin use with reduced cancer incidence. In diabetics receiving metformin (as opposed to other therapies), overall cancer incidence was lowered (odds ratio (OR) 0.86 and $95 \%$ confidence interval (95\% CI) $0 \cdot 73-1 \cdot 02$ ) and there was evidence of a dose response in relation to total duration of use or number of prescriptions dispensed. Since then, at least 17 epidemiological studies examining the association of metformin treatment of diabetes with cancer incidence and mortality have reported similar findings (see Table 1), and evidence has emerged that metformin use may reverse the increased cancer risk associated with administration of insulin or insulin secretagogues ( $\mathrm{Li}$ et al. 2009). A recent meta-analysis (Decensi et al. 2010) has identified a $31 \%$ reduction in overall cancer incidence or mortality when metformin is used in the treatment of diabetes. There is emerging evidence that metformin use is associated with reduced risk of several common cancers, including colorectal, pancreas, hepatocellular, breast and lung, although not all studies have identified significant effects. The reduced risk of obesity-associated cancers such as breast and colorectal is not surprising, given that metformin reduces insulin levels that appear to be important mediators of associations of obesity with cancer. Preclinical reports suggesting reduced tobaccocarcinogen-induced lung cancer burden with the use of metformin (Memmott et al. 2010), coupled with emerging clinical evidence that metformin may be associated with improved lung cancer outcomes (reviewed below Mazzone et al. (2010) and Tan et al. (2011)), suggest that other factors, such as nicotine, may lead to insulin resistance in individuals with smoking associated cancers or that non-insulin-mediated mechanisms of action are important.

Although epidemiological studies have fairly consistently reported reduced cancer incidence and/or mortality in diabetic patients who receive metformin in standard clinical doses $(1500-2250 \mathrm{mg} /$ day in adults), these studies have important methodological limitations. Most were conducted retrospectively and many sampled their cases from hospital or clinical registries rather than population-based registries, thereby limiting external validity and introducing potential selection biases. Inclusion criteria varied. Some studies did not exclude individuals with prior diagnosis of cancer, thus introducing a possible reverse causation bias. Other studies included both invasive and non-invasive cancers in their analyses (Bodmer $\mathrm{et}$ al. 2010). Many studies included patients exposed to a variety of treatments for diabetes complicating the analysis of metformin associations. Self-reporting of key variables such as concomitant medication use and cancer risk factors such as obesity, tobacco use and family history may have introduced exposure biases; imbalances in these factors, as well as others such as age and severity of diabetes, may have led to confounding of associations of metformin with cancer incidence or mortality. Nonetheless, it remains biologically plausible that metformin use may be causally associated with lower cancer incidence and mortality. However, caution should be exercised in translating these observations to non-diabetic patients because their physiological milieu and the cancers they develop may differ in important ways from the situation in diabetic patients. Notably, insulin resistance (characterised by high levels of circulating insulin and, in later stages, by high glucose levels with or without sustained high insulin levels) may have been present for many years before the clinical diagnosis of diabetes (Kendall \& Bergenstal 2001), leading to the development of insulin- and/or glucosedependent cancers that are more sensitive to insulinand/or glucose-lowering effects of metformin. Because of this, it is possible that similar physiological and/or anti-cancer effects may not be present in non-diabetics.

\section{Clinical}

Retrospective clinical data suggest that metformin use in diabetics may be associated with the development of cancers that differ from those seen in the absence of metformin. Specifically, in breast cancer, metformin use has been associated with tumours that are more 
Table 1 Epidemiological studies examining the association of metformin use by diabetics with cancer incidence and mortality

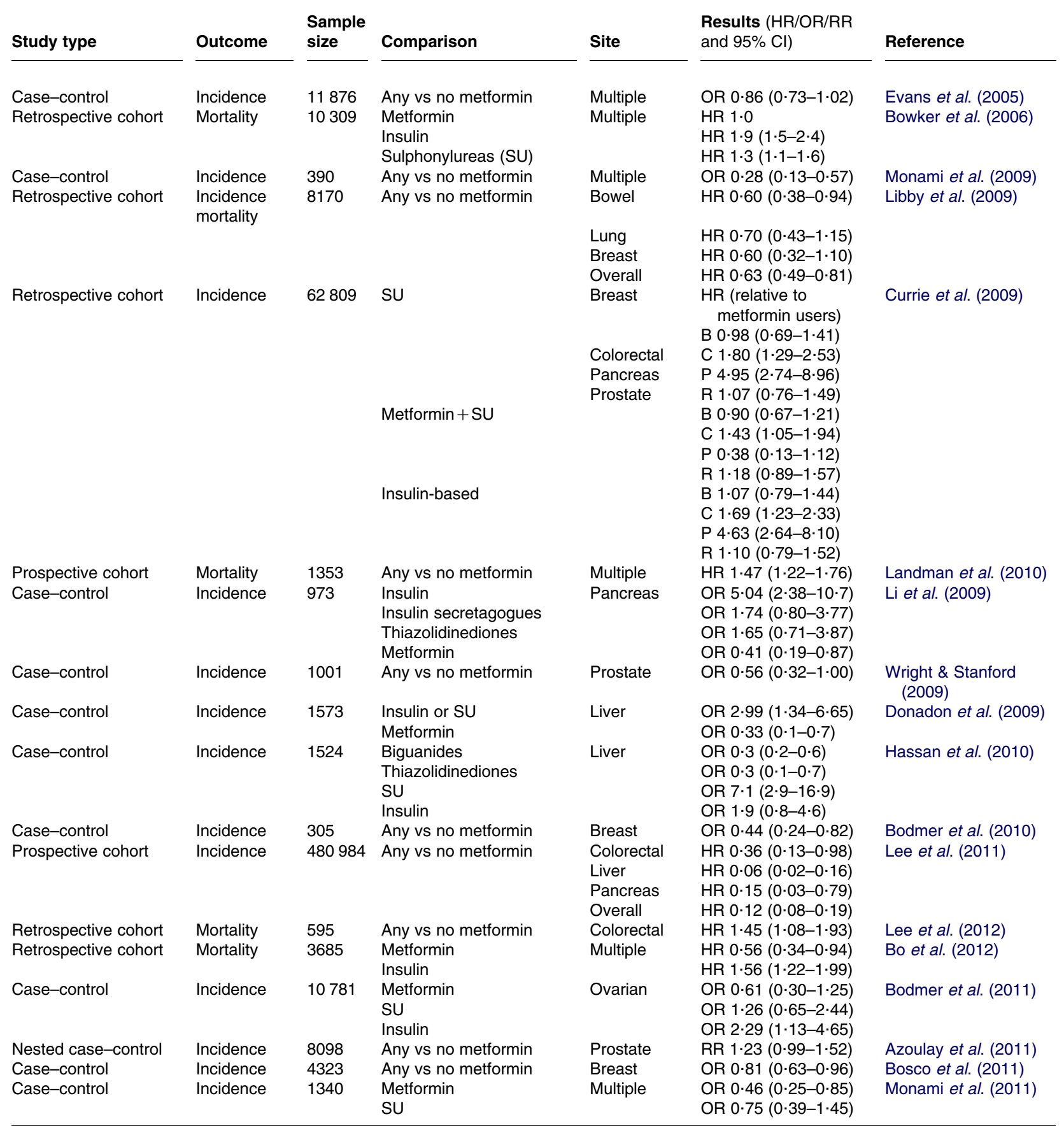

B, Breast Cancer; C, Colorectal Cancer; P, Pancreatic Cancer; R, Prostate Cancer; HR, Hazard Ratio; RR, Risk Ratio; OR, Odds Ratio.

frequently progesterone receptor $(\mathrm{PgR})$ positive (Berstein et al. 2010a) and less frequently triple negative (Meiers et al. 2010), whereas in lung cancer, metformin use has been associated with a higher frequency of adenocarcinomas (vs other histologies; Mazzone et al. 2010, Tan et al. 2011).

Similar retrospective data suggest that cancer outcomes may be better in diabetics with breast or lung cancer if they are receiving metformin. Jiralerspong et al. (2009) studied pathological complete response (pCR) rates in breast cancer patients receiving neoadjuvant chemotherapy - pCR was significantly higher in diabetics receiving metformin than in diabetics not receiving metformin (24 vs $8 \%$ ), with intermediate pCR in non-diabetics who were not 
exposed to metformin (16\%). Although imbalances in covariates such as age, obesity, insulin and taxane use were present, differences in PCR were significant in adjusted analyses; however, metformin use was not significantly associated with survival. Likewise, metformin use by patients with triple-negative breast cancer was not associated with beneficial effects on distant metastasis-free survival, recurrence-free survival or overall survival (Bayraktar et al. 2012). However, patients receiving metformin had a slightly lower risk of distant metastases (compared with diabetics not receiving metformin and non-diabetics). In a retrospective review of lung cancers in diabetics, Mazzone et al. (2010) reported more frequent occurrence of metastatic disease at diagnosis in those receiving insulin or thiazolidinediones (which also lower insulin; 20 vs $42 \%$ in those not receiving these agents, $P=0 \cdot 027$ ) and a reduced risk of death in those receiving metformin (hazard ratio (HR) 0.56, $P=0.056$ ). Recent evidence also suggests that chemotherapy outcomes may be improved by metformin in diabetic non-small cell lung cancer patients (Tan et al. 2011). Because of the retrospective design of these studies and the nonrandom allocation of metformin (and thiazolidinediones), these results should be considered as hypothesis generating. Nonetheless, they suggest that clinically important beneficial effects may result from metformin use in cancer patients.

Prospective data regarding metformin use in nondiabetic cancer patients are beginning to emerge. We have reported a $22 \%$ reduction in insulin levels when metformin is given to non-diabetic breast cancer survivors in a standard clinical dose of $1500 \mathrm{mg}$ /day (Goodwin et al. 2008). Hadad et al. (2011) have recently completed a preoperative, randomised, 'window of opportunity' trial examining the effects of metformin on non-diabetic women with operable invasive breast cancer. Metformin (1000 mg twice daily) was well tolerated and caused a significant reduction in Ki-67 staining in tumours and altered the expression of numerous genes including those involved in metabolism, inflammation and AMPK (PRKAA) and mTOR signalling. Interim data from additional ongoing neoadjuvant studies on breast cancer have provided evidence that metformin administration (in standard clinical dose) to newly diagnosed breast cancer patients is safe and has favourable effects on tumour cell proliferation and apoptosis in the absence of other anti-cancer treatment (Bonanni et al. 2010, Niraula et al. 2010). Furthermore, Hosono et al. (2010) have reported a randomised trial showing that a very low dose of metformin ( $250 \mathrm{mg}$ daily) reduces proliferation and aberrant crypt foci formation in the rectal epithelium of non-diabetic patients with previous colorectal polyps when compared with placebo. Completion of these studies, as well as planned and ongoing studies on the metastatic and adjuvant setting in breast, prostate, pancreatic and endometrial cancer (clinicaltrials.gov), will provide important additional information on the anti-cancer effects of metformin and help elucidate the clinically important mechanisms of metformin action in diabetic and non-diabetic cancer patients.

\section{Metabolic}

Obesity has been associated with increased overall cancer risk and increased risk of most common solid tumours and haematological malignancies (Calle et al. 2003); lung cancer is a notable exception to this association. Although many factors have been postulated to mediate effects of obesity on cancer, including sex hormones such as oestrogen, adipocytokines such as leptin and adiponectin, and inflammatory cytokines such as interleukins and tumour necrosis factor $\alpha$ $(\mathrm{TNF} \alpha$ ), recent research has focused on insulin (or insulin resistance as part of the metabolic/insulin resistance syndrome) as a potentially important mediator. In a number of meta-analyses (Everhart \& Wright 1995, Larsson et al. 2005, 2006, 2007, Mitri et al. 2008, Larsson \& Wolk 2011), type 2 diabetes (associated with a period of hyperinsulinaemia) has been associated with increased risk of common solid tumours including those of the breast, colon/rectum, pancreas and kidney but not the prostate (Kasper \& Giovannucci 2006, Kasper et al. 2009). Furthermore, higher insulin or C-peptide (cleaved from proinsulin when insulin is released) levels have also been associated with risk of breast, colorectal and other cancers (Pisani 2008). These observations provide credence to an insulinlowering mechanism of metformin action in cancer prevention.

In the setting of established cancer, higher levels of insulin or C-peptide have been independently associated with poor outcomes (increased risk of recurrence and death) in breast and prostate cancers (Goodwin et al. 2002, Pasanisi et al. 2006, Ma et al. 2008, Emaus et al. 2010, Duggan et al. 2011, Erickson et al. 2011, Irwin et al. 2011, Pritchard et al. 2011). Our group has demonstrated a more than doubled risk of distant recurrence and tripled risk of death in women with locoregional breast cancer whose insulin levels were in the highest quartile, even though those levels were within the normal range (Goodwin et al. 2002). In prostate cancer, this association may be limited to men with body mass index $(\mathrm{BMI})>25 \mathrm{~kg} / \mathrm{m}^{2}$ (Ma et al. 2008).

The presence of insulin receptors (IRs) on many cancers provides a biological rationale for the effects of insulin on cancer risk and prognosis - recent understanding of the nature of these receptors and the signalling pathways they activate when ligand binding occurs is reviewed in the following section. 


\section{Preclinical evidence}

\section{Mechanism of action of metformin as an anti-cancer agent}

The role of metformin in the inhibition of cancer is postulated to be associated with both direct and indirect effects of the drug, as shown in Fig. 2. The indirect effects are linked to the ability of metformin to inhibit the transcription of key gluconeogenesis genes in the liver and stimulate glucose uptake in muscle, thus increasing insulin sensitivity and reducing blood glucose and lowering insulin levels. The direct effects of metformin are believed to be primarily mediated by activation of AMPK, a serine/threonine protein kinase involved in regulating cellular energy metabolism, leading to a reduction in mTOR signalling and protein synthesis in cancer cells. Metformin activates AMPK by inhibiting complex I of the mitochondrial respiratory chain, which leads to impaired mitochondrial function and conditions that effectively mimic cellular energy stress (El-Mir et al. 2000, Brunmair et al. 2004). Examples of these stresses include glucose deprivation, hypoxia, oxidative stress, ischaemia and muscle contraction or exercise, all of which lead to an increase in the ratio of AMP:ATP and activation of

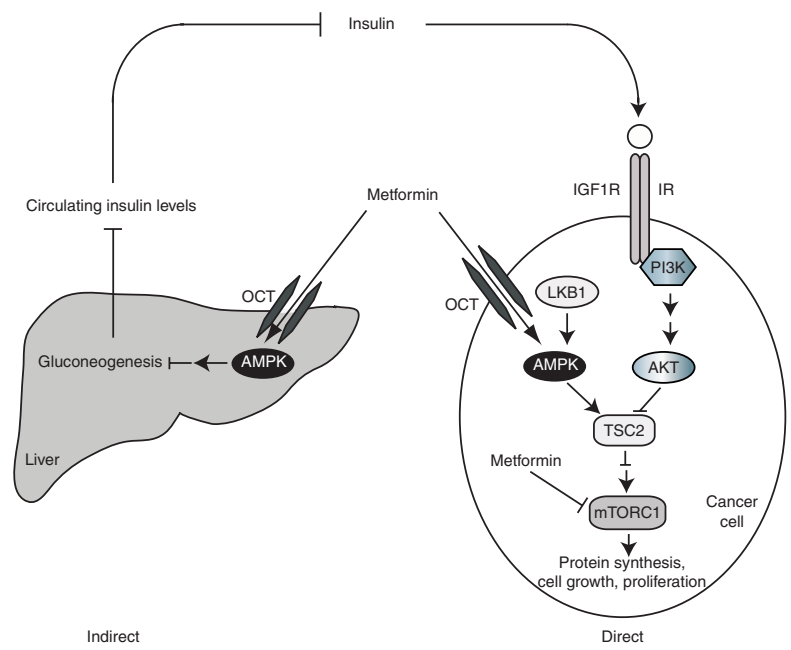

Figure 2 Mechanism of action of metformin in cancer. The anticancer activity of metformin is associated with direct and indirect effects of the drug. The direct insulin-independent effects of metformin are mediated by activation of AMPK and a reduction in mTOR signalling and protein synthesis in cancer cells. The tumour suppressors LKB1 and TSC2 are important in mediating the effects of metformin on AMPK and mTOR respectively; however, metformin may also inhibit mTOR independently of LKB1, AMPK and TSC2. The indirect insulin-dependent effects of metformin are mediated by its ability to activate AMPK and inhibit gluconeogenesis in the liver and stimulate glucose uptake in muscle. The resulting reduction in circulating insulin alleviates activation of PI3K/AKT/mTOR signalling in cancer cells. The cell membrane transporter OCT1 is required for metformin uptake in tissue and therefore may play a key role in efficacy.
AMPK (Kahn et al. 2005). The resulting increase in AMP activates AMPK by at least three separate mechanisms (Long \& Zierath 2006): i) allosteric activation, ii) promotion of activation-specific phosphorylation of the $\alpha$ catalytic subunit on residue Thr172 by the upstream kinase LKB1 (STK11) and iii) interference with deposphorylation of AMPK Thr172 by protein phosphatases. Upon activation, AMPK phosphorylates a number of effectors leading to the activation of ATP-generating pathways, such as glycolysis and fatty acid oxidation, and the inhibition of ATP-consuming pathways, such as fatty acid and protein synthesis (Kahn et al. 2005).

\section{Direct (insulin-independent) effects of metformin}

Protein synthesis is one of the most energy-consuming processes in the cell and, as such, is a major target of AMPK signalling under conditions of cellular energy stress. Upon activation by metformin, AMPK phosphorylates TSC2, stimulating its GTPase-activating protein (GAP) activity towards the small GTPase RHEB, which causes a reduction in mTOR signalling (Inoki et al. 2003). mTOR controls protein synthesis by regulating the phosphorylation of key proteins involved in mRNA translation, such as the 4E-BPs, S6Ks and the initiation factor eIF4G. Inhibition of mTOR signalling leads to a reduction in phosphorylation of its major downstream effectors, the 4E-BPs and S6Ks, and a net inhibition of global protein synthesis (Zakikhani et al. 2006, Dowling et al. 2007; Fig. 2). Reduced protein synthesis is thought to be an important mechanism of direct metformin action in the inhibition of cancer cell proliferation. Indeed, the growth-suppressive effect of metformin in breast cancer cell lines was associated with a suppression of mTOR signalling and a general inhibition of protein synthesis (Zakikhani et al. 2006, Dowling et al. 2007).

Considering the complexity of the molecular cascade mediating the effect of metformin on protein synthesis, the status of several factors can impact metformin sensitivity. For instance, in mouse embryonic fibroblasts (MEFs), loss of TSC2 leads to resistance to the effects of metformin on mTOR signalling, protein synthesis and cell proliferation (Dowling et al. 2007). Nevertheless, a recent report demonstrates that in MEFs, AMPK can directly suppress mTOR in the absence of TSC2 by phosphorylating the mTOR-associated adaptor protein raptor (Gwinn et al. 2008). The tumour suppressor LKB1 is also an important determinant of metformin sensitivity. As indicated earlier, LKB1 is the immediate AMPK activator in response to cellular energy stress and phosphorylates a key AMPK residue (Thr172) obligate for catalytic activity. Cells lacking LKB1 exhibit decreased AMPK activation and elevated mTOR signalling even under conditions of cellular energy stress or treatment with AMPK agonists (Shaw et al. 2004). LKB1 
is also required for metformin-mediated AMPK activation. A variety of cells lacking LKB1, including those derived from breast and cervical cancers and mouse embryonic stem cells, are resistant to the growth inhibitory effects of metformin in vitro (Zakikhani et al. 2006, Dowling et al. 2007, Huang et al. 2008). Moreover, LKB1 is required for liver AMPK activation and the associated reduction in blood glucose in response to metformin treatment (Shaw et al. 2005). Thus, LKB1 and TSC2 represent key factors in determining tumour sensitivity to the effects of metformin.

Increased mTOR-dependent protein synthesis and cell growth are hallmark features of tumorigenesis downstream of the activated PI3K/AKT signalling pathway, one of the most frequently deregulated molecular networks in human breast cancer. Activating mutations in the PI3K catalytic subunit (PIK3CA) have been found in 20-35\% of primary breast specimens (Bachman et al. 2004, Lee et al. 2005), while mutations or loss of the tumour suppressor PTEN, a negative regulator of the PI3K/AKT cascade, has been found in up to $40 \%$ of breast tumours (Sansal \& Sellers 2004, Perez-Tenorio et al. 2007). In addition, over-expression of HER2 (ERBB2), an upstream activator of PI3K, is observed in $30 \%$ of human breast cancers (Yu \& Hung 2000). Notably, PI3K/AKT signalling correlates with breast cancer progression and contributes to resistance of breast cancer cells to chemotherapy, trastuzumab and tamoxifen (Zhou et al. 2004, Morgensztern \& McLeod 2005). A number of physiological stimuli, including a variety of growth factors and hormones such as insulin, also activate PI3K signalling in cancer cells. Considering the prevalence of genetic changes leading to elevated mTOR signalling, targeting this cascade using metformin represents a possibly viable therapeutic option in breast cancer.

In addition to mTOR, other targets of AMPK may also be implicated in cancer cell proliferation and survival. For example, AMPK phosphorylates p53 (a tumour suppressor that is a downstream target of AMPK) upon energy stress in MEFs leading to activation of a cell cycle checkpoint, allowing cells to survive periods of energy deprivation (Jones et al. 2005). p53 may also impact sensitivity to metformin. Metformin inhibited the growth of p53-deficient human colon carcinoma cells in vitro and in tumour xenografts in mice but had no effect on p53 wild-type cells (Buzzai et al. 2007). This difference in sensitivity was attributed to the ability of p53 wild-type cells to undergo a metabolic adaptation, which maintained cell survival during periods of metformin-mediated AMPK activation. However, p53 status did not impact metformin sensitivity in other cancer cell lines (Zhuang \& Miskimins 2008, Alimova et al. 2009). Sensitivity to the anti-tumoral effects of metformin may also be governed by expression levels of the organic cation transporters (OCT1 (SLC22A1), -2
(SLC22A2), and -3 (SLC22A3)). OCT1 is primarily responsible for metformin transport into cells and polymorphisms in the gene encoding OCT1 that affect hepatic uptake of metformin in vitro and have been associated with decreased efficacy in patients (Shu et al. 2007, Jin et al. 2009, Tzvetkov et al. 2009, Memmott et al. 2010). OCT1 is highly expressed in liver tissue, with lower levels present in the kidney and minimal levels present in the lung and small intestine (Jin et al. 2009, Tzvetkov et al. 2009, Memmott et al. 2010). Little is known about the expression of OCT1 in human tumours; however, an assessment of its expression patterns in tumour tissue will be critical to elucidate the mechanism of anti-tumour action of metformin and the identification of patients best suited for metformin therapy.

Recent reports have raised the possibility that metformin exhibits additional inhibitory effects on gluconeogensis and mTOR signalling independent of AMPK and TSC2 (Gwinn et al. 2008, Foretz et al. 2010, Kalender et al. 2010). Metformin inhibited mTOR activity in cells lacking TSC2 and AMPK by suppressing RAG GTPases, which are involved in mTOR activation (Kalender et al. 2010). Furthermore, metformin lowered hepatic gluconeogenesis in the absence of AMPK, or its kinase, LKB1, by reducing hepatic energy levels (Foretz et al. 2010). These observations highlight the need for additional research focusing on the mechanism of action of metformin. Nevertheless, it appears likely that the ability of metformin to exert direct effects on mTOR signalling and indirect effects on circulating insulin remain integral to its potential mechanism of action in the treatment of cancer.

\section{Indirect (insulin-dependent) effects of metformin}

As noted earlier, metformin may also exhibit indirect effects on tumour growth by reducing circulating glucose and insulin levels via inhibition of hepatic gluconeogenesis and stimulation of glucose uptake in muscle (Fig. 2). High insulin levels associated with obesity, insulin resistance and type 2 diabetes may promote tumourigenesis via activation of the foetal isoform of the IR-A, which is highly expressed in human breast cancer. The IR lies upstream of a number of growth-promoting pathways including the PI3K/ AKT/mTOR signalling network (Belfiore \& Frasca 2008, Pollak 2008). The IGF1R, also proposed to be involved in breast cancer, is less highly expressed in breast tumours but may hybridise with IR-A to bind insulin and stimulate proliferation of breast cancer cells at concentrations that do not activate IGF1R dimers (Papa \& Belfiore 1996, Mulligan et al. 2007). Together, these observations suggest that, unlike normal adult epithelial cells, breast cancer cells may acquire sensitivity to the growth and survival effects of insulin. 
Reduction in insulin levels by metformin may counter act this sensitivity by reducing ligand binding to IR-A/IGF1R, indirectly inhibiting tumour growth and improving breast cancer outcomes.

\section{In vivo models of anti-tumour activity of metformin}

The effects of metformin on spontaneous breast tumour development have been examined in MMTV$\mathrm{Her} 2 / \mathrm{Neu}$ transgenic mice that exhibit mammaryspecific expression of the HER2/NEU oncoprotein, resulting in the almost universal development of focal mammary adenocarcinomas, which metastasise to the lungs. Metformin treatment, in a dose comparable to that used clinically in humans, significantly delayed the appearance of mammary adenocarcinomas, reduced the size of tumours and prolonged the lifespan of MMTV-Her2/Neu mice (Anisimov et al. 2005). These effects were accompanied by a significant reduction in blood glucose and a statistically non-significant diminution in circulating insulin levels (Anisimov et al. 2005). In mice heterozygous for the tumour suppressor PTEN (highly prone to tumours in various organs), metformin (administered at a dose of $300 \mathrm{mg} / \mathrm{kg}$ body weight per day, more than tenfold higher than the standard clinical dose) delayed tumour onset by $25 \%$ (Huang et al. 2008), an effect that required LKB1-mediated AMPK activation. Metformin was also effective in reducing the growth of intestinal polyps in mice deficient for the tumour suppressor APC (Tomimoto et al. 2008).

Orally administered metformin (at plasma levels $(2 \cdot 7-10 \cdot 3 \mu \mathrm{M})$ equivalent to those achieved in patients $(2 \cdot 8-15 \mu \mathrm{M}))$ also reduced tobacco carcinogeninduced lung tumourigenesis (4-(methylnitrosamino)1-(3-pyrdyl)-1-butanone (NNK)) in mice (tumour burden reduced by 53\%; Memmott et al. 2010). Intraperitoneal administration, resulting in higher plasma levels of metformin $(24 \cdot 2 \mu \mathrm{M})$, reduced tumour burden by $72 \%$. Although AMPK activation was observed in the liver and circulating insulin levels were reduced after i.p. injection, metformin failed to activate AMPK in lung tumour tissue. A concomitant reduction in phosphorylation of IGF1R/IR, AKT and ribosomal protein S6 in tumours suggests that the indirect (insulin-mediated) effects of metformin were responsible for the reduction in lung tumour burden.

In addition to spontaneous and carcinogen-induced tumours, metformin has been found to impact growth in mouse xenograft and syngeneic tumour models - the tumour cells injected in these models were grown in culture media that contained high levels of glucose, insulin and other growth factors. In at least two syngeneic model systems (Lewis lung carcinoma LLC1 cells in C57BL/6J mice and triple negative 66c14 cells in Balb/c mice), metformin (at doses comparable to human doses in the former and $\sim 40$ times higher than human doses in the latter) reduced tumour growth when mice were fed a high-energy diet (which induces weight gain and insulin resistance; Algire et al. 2008, Phoenix et al. 2010). In these models, the high-energy diet enhanced tumourigenesis, whereas metformin significantly reduced the effect of this diet on tumour growth. Metformin improved insulin sensitivity in tumour-bearing high-energy diet fed mice and resulted in AMPK activation and reduced IR-mediated signalling in tumours. Paradoxically, metformin failed to inhibit the growth of tumours in mice on a control diet, despite activation of AMPK in tumour tissue (Algire et al. 2008). These observations are consistent with an indirect, insulin-lowering mechanism of metformin action; however, it must be recognised that the tumour cells were dependent on high insulin levels in culture medium before their injection into mice and mechanisms may differ in the clinical setting in which this dependence is not present.

\section{In vitro models of anti-cancer effects of metformin}

In vitro work focusing on the effects of metformin on breast cancer cells demonstrated that metformin inhibited the growth of a variety of breast cancer cells regardless of oestrogen receptor (ER), PR, HER2 or p53 status (Zhuang \& Miskimins 2008, Alimova et al. 2009). Recently, it was reported that metformin induced unique responses in the triple-negative (ER, PR and HER2 negative) breast cancer cell line MDAMB231, leading to an S phase cell cycle arrest, reduced cell proliferation and colony formation, as well as increased apoptosis (Liu et al. 2009). In this system, metformin also induced AMPK activation, reduced the phosphorylation of epidermal growth factor receptor (EGFR), MAPK and Src and lowered the levels of cyclins D1 and E (Liu et al. 2009). Growth inhibitory effects were recapitulated in vivo where metformin significantly reduced the growth of triple-negative breast cancer cell xenografts in nude mice. Some of the anticancer effects of metformin on triple-negative breast cancer cells were also associated with STAT3 inhibition. Treatment of triple-negative cells with metformin led to a reduction in STAT3 activation and downstream signalling and metformin acted synergistically with a STAT3 inhibitor to decrease cell growth and induce apoptosis (Deng et al. 2012). Metformin may also be effective against ER-positive breast cancers by inhibiting aromatase expression in tumour stroma. In primary human breast adipose stromal cells, metformin treatment led to an increase in the phosphorylation of AMPK, which was associated with an inhibition of nuclear translocation of CRTC2, a CREB co-activator known to increase aromatase expression (Brown et al. 2010). Furthermore, metformin interacted additively with tamoxifen to reduce 
breast cancer cell proliferation (Berstein et al. 2010b). These results indicate that metformin may represent a potentially effective therapy in women with ER-positive breast tumours.

Emerging evidence indicates that breast cancer cells over-expressing Her2, either through gene amplification or ectopic expression, exhibit increased sensitivity to the growth inhibitory effects of metformin (Vazquez-Martin et al. 2009). The effects of metformin were associated with translational suppression of HER2 protein expression mediated by the inhibition of S6K1, a downstream effector of mTOR (Vazquez-Martin et al. 2009). Of interest, the mTOR inhibitor rapamycin caused similar translational suppression of erbB3 (an EGFR, also known as HER3 in humans) in breast cancer cells and mammary tumours in mice (Liu et al. 2005). Taken together, these data indicate that metformin and other inhibitors of mRNA translation act by reducing translation of mRNAs encoding specific growth factor receptors. Metformin also exhibited inhibitory effects on trastuzumab-resistant breast cancer cells. In trastuzumab-resistant models, metformin disrupted ERBB2/IGF1R complexes and significantly reduced cell proliferation (Liu et al. 2011).

Metformin has also been reported to exert antiproliferative effects against a number of other cancer cell types including those derived from prostate, endometrial and brain tumours (Isakovic et al. 2007, Ben Sahra et al. 2008, Cantrell et al. 2010). In prostate cancer cells, metformin treatment caused a G1 cell cycle arrest (mediated by a reduction in cyclin D1 levels and phosphorylation of $\mathrm{Rb}$ ), as well as an increase in the levels of the cell cycle inhibitor p27kip, resulting in a strong anti-proliferative effect both in vitro and in tumour xenografts in mice (Ben Sahra et al. 2008). In endometrial cancer cells, metformin induced a G1 arrest and at high doses caused apoptosis while suppressing mTOR signalling (Cantrell et al. 2010). Finally, while causing cell cycle arrest in low-density cultures of rat glioma cells, metformin induced apoptosis in confluent cell cultures (Isakovic et al. 2007).

A major obstacle in the effective treatment of breast and other cancers is the resistance of tumour cells to drug therapy. The existence of tumour-initiating (stem) cells, a specific subset of tumour cells that are believed to be involved in tumour initiation, progression, heterogeneity and recurrence, has been proposed as one of the underlying causes of this resistance (Campbell \& Polyak 2007, Polyak \& Weinberg 2009). Metformin specifically inhibited the growth of $\mathrm{CD} 44^{+} / \mathrm{CD} 24^{\text {to }}$ (a putative stem cell marker signature; Hirsch et al. 2009) cells in culture and reduced their ability to form tumours when injected into nude mice. When metformin was combined with doxorubicin, a striking reduction in both $\mathrm{CD} 44^{+} / \mathrm{CD} 24^{\text {lo }}$ and other cancer cells was observed; this combination was also effective in preventing tumour growth and relapse in mice (Hirsch et al. 2009, Iliopoulos et al. 2011). Significantly, no CD $44^{+} / \mathrm{CD} 24^{\text {lo }}$ cells could be isolated from mice after metformin treatment, raising the possibility that metformin may specifically target tumour-initiating cells. Metformin was also effective in preventing tumour relapse in mice when combined with the standard chemotherapeutic agents paclitaxel and carboplatin, highlighting the potential application of metformin as part of a combinatorial therapeutic strategy (Iliopoulos et al. 2011). However, in some experiments the regimen of metformin administration complicates the interpretation of results (Hirsch et al. 2009). Large volumes (up to $0.5 \mathrm{ml}$ ) of metformin solution were directly injected into tumour xenografts, likely resulting in exposure of tumour cells to nonphysiological doses of the drug, as well as necrosis (due to direct tumoral injection). It is unclear how a comparable drug delivery can be achieved in patients. Nonetheless, these data imply a possible benefit in combining metformin with standard chemotherapies in breast cancer treatment.

\section{Limitations of preclinical models}

One of the major limitations in interpreting many preclinical studies is the high concentration of metformin used in vitro in relation to the concentration that can be safely obtained in the clinical setting (Fig. 3). Most in vitro studies report using doses of metformin between 1 and $40 \mathrm{mM}(165-6600 \mathrm{mg} / \mathrm{l})$, which is well above the feasible therapeutic plasma levels $(0 \cdot 465-2 \cdot 5 \mathrm{mg} / 1$ or $2 \cdot 8-15 \mu \mathrm{M})$ in humans (Stambolic et al. 2009). Thus, it is possible that metformin caused a degree of energy stress (and resulting AMPK activation) in these studies that far exceeds effects that would be seen clinically. For example, Phoenix et al. (2009); reported pro-angiogenic effects of

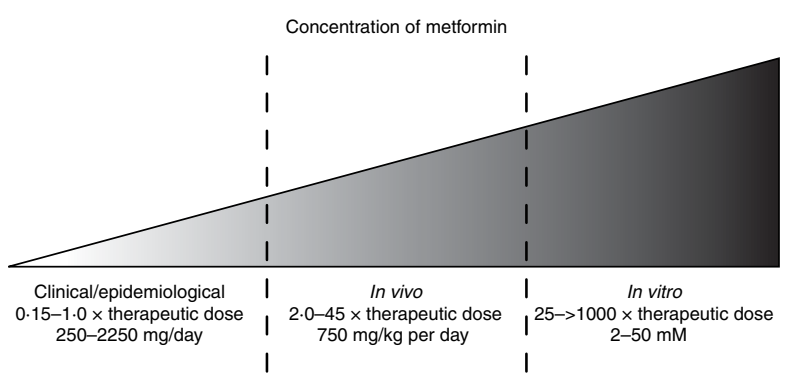

Figure 3 Concentrations of metformin used in clinical and preclinical studies. The anti-cancer effects of metformin have been tested over a wide range of doses. Clinical and epidemiological studies have utilised metformin at standard doses of up to $2250 \mathrm{mg} /$ day. Conversely, preclinical studies often involve extremely high, non-physiological concentrations of metformin that are in excess of the therapeutic levels achieved in human patients. 
metformin in a mouse xenograft model; however, metformin concentrations were hundreds of times higher than those that are deemed safe clinically; it is possible that these extremely high concentrations led to intracellular metabolic stresses (and responses to those stresses) beyond those that would be seen clinically, raising questions as to whether such pro-angiogenic effects are clinically relevant.

Nonetheless, recent studies indicate that metformin is effective at reducing cancer cell proliferation in vitro at concentrations as low as $10 \mu \mathrm{M}$, well within the therapeutic range of the drug (Liu et al. 2009). Moreover, metformin is capable of inhibiting tumour growth in mouse models at doses equivalent to those used in humans without causing toxicity (Anisimov et al. 2005, Ben Sahra et al. 2008). Importantly, only slight levels of AMPK activation are required to trigger downstream signalling events (Hawley et al. 2002).

Another concern arises from the growth conditions of the cell culture models used to assess the inhibitory effects of metformin in vitro. The majority of cancer cell lines are grown in culture media that contains extremely high amounts of growth factors and glucose. For example, average tissue culture media contains glucose at concentrations between 10 and $25 \mathrm{mM}$, well above the fasting levels of glucose observed in nondiabetic patients $(<6 \mathrm{mM})$. Most media is also supplemented with $5-10 \%$ foetal bovine serum, which contains high concentrations of growth factors and hormones, including insulin and EGF. Thus, cancer cell lines are often maintained in non-physiological conditions that are optimised for maximum growth and proliferation. The excessive concentrations of insulin, glucose and growth factors in culture media, combined with the presence of oncogenic mutations and variable expression of the membrane transporter OCT1, may account for the elevated doses of metformin required to elicit cellular responses in vitro.

A host response is not present in vitro, and as a result, the direct (insulin-independent) mechanism(s) of metformin action have been the focus of this research. Because many of the conditions evaluated in this in vitro work are outside the boundaries possible in the clinical setting, it is conceivable that many of the direct effects of metformin reported in in vitro work will not be relevant in the clinical situation.

Thus, although a beneficial anti-cancer effect of metformin at lower concentrations that are encountered clinically remains plausible, mechanistic effects identified in the preclinical studies may differ from those that are most relevant in the clinical setting. It is therefore necessary to exercise caution in further studies of the effects of metformin in vitro. Careful dosing, equivalent to therapeutic levels in vivo, and strategies for varying the levels of insulin and glucose within culture media are required for physiological modelling of metformin in vitro. It is anticipated that such models will be more likely to inform clinical studies.

\section{Translational challenges}

The anti-cancer effects of metformin are associated with both direct (insulin-independent) and indirect (insulin-dependent) actions of the drug. This duality of action has increased the complexity of clinical evaluation of metformin, including the translation of preclinical observations. Existing preclinical, clinical and epidemiological evidence has incorporated a broad range of insulin, glucose and metformin concentrations and has often focused on different potential mechanisms of metformin action (Fig. 3). Effects that have been identified in preclinical work, including differential effects in different molecular subtypes of breast cancer, although plausible, require confirmation in the clinical setting. Focused research in the neoadjuvant and metastatic settings, with biopsies preand post-metformin administration, and concurrent evaluation of physiological effects will help to elucidate the clinical relevance of these effects.

Differentiation of the relative importance of indirect (insulin-mediated) and direct (insulin-independent) metformin effects is critical for optimal evaluation of this agent. The postulated mechanisms of action give rise to a broad range of therapeutic targets, leading to a large number of potential clinical markers of metformin benefit (Table 2). Understanding the relative importance of therapeutic targets and markers of benefit is required for appropriate selection of patients who might benefit from metformin. For example, if indirect insulin-mediated effects of metformin predominate, patient selection should target individuals with

Table 2 Predictors of metformin benefit in human cancer

Indirect
effect
(insulin-
dependent)

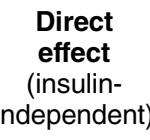

Host

High BMI

Physical inactivity

High fasting insulin

Insulin resistance

OCT1/2/3 expression (liver)

Tumour

IR/IGF1R expression

Increased $\mathrm{PI} 3 \mathrm{~K} / \mathrm{mTOR}$

OCT1/2/3 expression

LKB1 expression

TSC2 expression

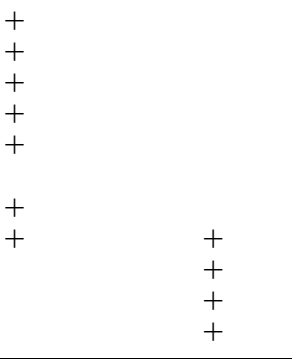


high insulin levels and/or obesity, germline expression of OCTs (particularly OCT1) and tumour characteristics including IR/IGF1R expression and PI3K pathway activation. In contrast, if direct (insulin-independent) mechanisms of metformin action are key, tumour characteristics such as LKB1 and TSC2 expression, OCT1 positivity and PI3K/AKT/mTOR activation will likely emerge. It is possible that the predominant mechanism of metformin action (and key markers of activity) will differ across types of tumours. Once key mechanisms of action (and their associated markers) are understood, metformin can be used in a targeted fashion, incorporating patient and tumour attributes consistent with known mechanisms of action.

Although evidence of direct (insulin-independent) anti-cancer effects of metformin that has arisen from preclinical research is strong, leading to a focus on these direct effects by many researchers, emerging clinical and in vivo data suggest that indirect insulinmediated effects of metformin may be of key importance in at least some common cancers, including breast and lung. If this is borne out by ongoing and future research, the focus of preclinical research will need to shift to models that incorporate these indirect effects, requiring more complex designs than are currently used in most in vitro research. Similarly, investigation of markers of metformin benefit will need to include key host factors such as circulating insulin and glucose levels, obesity and germline OCT1 expression, in addition to attributes of tumour cells such as insulin/ IGF1 receptor expression that can potentially mediate these indirect, host-mediated effects and any direct effects that are relevant (Table 2).

Going forward, care is required to maximise the efficiency of evaluation of metformin as a potential anti-cancer agent. The known safety profile of the agent allows rapid evaluation and has led to the initiation of at least one large-scale Phase III adjuvant trial (NCIC CTG MA.32) in the breast cancer setting (Goodwin et al. 2011). Several neoadjuvant studies are ongoing, and studies on the metastatic and prevention settings are ongoing and planned in a number of cancer types. It is essential that these studies include strong embedded correlative research components, with evaluation of host and tumour factors to identify potential predictors of metformin benefit and, more importantly, to allow enhanced understanding of the relative contributions of indirect insulin-mediated and direct insulin-independent metformin action. The absence of pharmaceutical industry interest in metformin (due to its generic status) has led to less co-ordination of research activities than is commonly seen in anti-cancer drug development - as a result, it is essential that the research community ensures that this function is fulfilled and that a major focus on clinical translation and relevance emerges in future research.

\section{Declaration of interest}

P J G is the principal investigator and V S is the correlative science chair of a Phase III adjuvant metformin trial (NCIC CTG MA.32). Apotex Canada, a generic drug company, supplies drug and placebo to NCIC CTG for use in this trial.

\section{Funding}

The authors would like to acknowledge support from the Canadian Breast Cancer Foundation, the Ontario Institute for Cancer Research, the Canadian Cancer Society Research Institute, the Susan G Komen for the Cure Foundation and the Breast Cancer Research Foundation. R J O D is supported by a Banting Postdoctoral Fellowship from the Canadian Institutes of Health Research.

\section{References}

Algire C, Zakikhani M, Blouin MJ, Shuai JH \& Pollak M 2008 Metformin attenuates the stimulatory effect of a high-energy diet on in vivo LLC1 carcinoma growth. Endocrine-Related Cancer 15 833-839. (doi:10.1677/ERC-08-0038)

Alimova IN, Liu B, Fan Z, Edgerton SM, Dillon T, Lind SE \& Thor AD 2009 Metformin inhibits breast cancer cell growth, colony formation and induces cell cycle arrest in vitro. Cell Cycle 8 909-915. (doi:10.4161/cc.8.6.7933)

Anisimov VN, Berstein LM, Egormin PA, Piskunova TS, Popovich IG, Zabezhinski MA, Kovalenko IG, Poroshina TE, Semenchenko AV, Provinciali M et al. 2005 Effect of metformin on life span and on the development of spontaneous mammary tumors in HER-2/neu transgenic mice. Experimental Gerontology 40 685-693. (doi:10.1016/j.exger.2005.07.007)

Azoulay L, Dell'Aniello S, Gagnon B, Pollak M \& Suissa S 2011 Metformin and the incidence of prostate cancer in patients with type 2 diabetes. Cancer Epidemiology, Biomarkers $\mathcal{E}$ Prevention 20 337-344. (doi:10.1158/1055-9965.EPI-10-0940)

Bachman KE, Argani P, Samuels Y, Silliman N, Ptak J, Szabo S, Konishi H, Karakas B, Blair BG, Lin C et al. 2004 The PIK3CA gene is mutated with high frequency in human breast cancers. Cancer Biology $\mathcal{E}$ Therapy 3 772-775. (doi:10.4161/cbt.3.8.994)

Bayraktar S, Hernadez-Aya LF, Lei X, Meric-Bernstam F, Litton JK, Hsu L, Hortobagyi GN \& Gonzalez-Angulo AM 2012 Effect of metformin on survival outcomes in diabetic patients with triple receptor-negative breast cancer. Cancer 118 1202-1211. (doi:10.1002/cncr.26439)

Belfiore A \& Frasca F 2008 IGF and insulin receptor signaling in breast cancer. Journal of Mammary Gland Biology and Neoplasia 13 381-406. (doi:10.1007/s10911-008-9099-z)

Ben Sahra I, Laurent K, Loubat A, Giorgetti-Peraldi S, Colosetti P, Auberger P, Tanti JF, Le Marchand-Brustel Y \& Bost F 2008 The antidiabetic drug metformin exerts an antitumoral effect in vitro and in vivo through a decrease of cyclin D1 level. Oncogene $\mathbf{2 7}$ 3576-3586. (doi:10.1038/sj.onc.1211024)

Berstein LM, Boyarkina MP, Tsyrlina EV, Turkevich EA \& Semiglazov VF $2010 a$ More favorable progesterone receptor phenotype of breast cancer in diabetics treated with metformin. Medical Oncology 28 1260-1263. (doi:10.1007/s12032-010-9572-6)

Berstein LM, Yue W, Wang JP \& Santen RJ $2010 b$ Isolated and combined action of tamoxifen and metformin in wild-type, tamoxifen-resistant, and estrogen-deprived MCF-7 cells. Breast Cancer Research and Treatment 128 109-117. (doi:10.1007/s10549010-1072-z) 
Bo S, Ciccone G, Rosato R, Villois P, Appendino G, Ghigo E \& Grassi G 2012 Cancer mortality reduction and metformin. A retrospective cohort study in type 2 diabetic patients. Diabetes, Obesity $\mathcal{E}$ Metabolism 14 23-29. (doi:10.1111/j.1463-1326.2011.01480.x)

Bodmer M, Meier C, Krahenbuhl S, Jick SS \& Meier CR 2008 Metformin, sulfonylureas, or other antidiabetes drugs and the risk of lactic acidosis or hypoglycemia: a nested case-control analysis. Diabetes Care 31 2086-2091. (doi:10.2337/dc08-1171)

Bodmer M, Meier C, Krahenbuhl S, Jick SS \& Meier CR 2010 Longterm metformin use is associated with decreased risk of breast cancer. Diabetes Care 33 1304-1308. (doi:10.2337/dc09-1791)

Bodmer M, Becker C, Meier C, Jick SS \& Meier CR 2011 Use of metformin and the risk of ovarian cancer: a case-control analysis. Gynecological Oncology 123 200-204. (doi:10.1016/j.ygyno. 2011.06.038)

Bonanni B, Cazzaniga M, Puntoni M, Pruneri G, Serrano D, Lazzeroni M, Guerrieri-Gonzaga A, Macis D, Luini A, Veronesi A, et al. 2010 A randomized pre-surgical trial of metformin in breast cancer. Preliminary feasibility and safety results. San Antonio Breast Cancer Symposium, (PD03-02).

Bosco JL, Antonsen S, Sorensen HT, Pedersen L \& Lash TL 2011 Metformin and incident breast cancer among diabetic women: a population-based case-control study in Denmark. Cancer Epidemiology, Biomarkers \& Prevention 20 101-111. (doi:10.1158/ 1055-9965.EPI-10-0817)

Bowker SL, Majumdar SR, Veugelers P \& Johnson JA 2006 Increased cancer-related mortality for patients with type 2 diabetes who use sulfonylureas or insulin. Diabetes Care 29 254-258. (doi:10.2337/ diacare.29.02.06.dc05-1558)

Brown KA, Hunger NI, Docanto M \& Simpson ER 2010 Metformin inhibits aromatase expression in human breast adipose stromal cells via stimulation of AMP-activated protein kinase. Breast Cancer Research and Treatment 123 591-596. (doi:10.1007/s10549-010-0834-y)

Brunmair B, Staniek K, Gras F, Scharf N, Althaym A, Clara R, Roden M, Gnaiger E, Nohl H, Waldhausl W et al. 2004 Thiazolidinediones, like metformin, inhibit respiratory complex I: a common mechanism contributing to their antidiabetic actions? Diabetes 53 1052-1059. (doi:10.2337/diabetes.53.4.1052)

Buzzai M, Jones RG, Amaravadi RK, Lum JJ, DeBerardinis RJ, Zhao F, Viollet B \& Thompson CB 2007 Systemic treatment with the antidiabetic drug metformin selectively impairs p53-deficient tumor cell growth. Cancer Research 67 6745-6752. (doi:10.1158/ 0008-5472.CAN-06-4447)

Calle EE, Rodriguez C, Walker-Thurmond K \& Thun MJ 2003 Overweight, obesity, and mortality from cancer in a prospectively studied cohort of U.S. adults. New England Journal of Medicine $\mathbf{3 4 8}$ 1625-1638. (doi:10.1056/NEJMoa021423)

Campbell LL \& Polyak K 2007 Breast tumor heterogeneity: cancer stem cells or clonal evolution? Cell Cycle 6 2332-2338. (doi:10.4161/ cc.6.19.4914)

Cantrell LA, Zhou C, Mendivil A, Malloy KM, Gehrig PA \& Bae-Jump VL 2010 Metformin is a potent inhibitor of endometrial cancer cell proliferation - implications for a novel treatment strategy. Gynecological Oncology 116 92-98. (doi:10.1016/j.ygyno.2009.09.024)

Currie CJ, Poole CD \& Gale EA 2009 The influence of glucoselowering therapies on cancer risk in type 2 diabetes. Diabetologia 52 1766-1777. (doi:10.1007/s00125-009-1440-6)

Decensi A, Puntoni M, Goodwin P, Cazzaniga M, Gennari A, Bonanni B \& Gandini S 2010 Metformin and cancer risk in diabetic patients: a systematic review and meta-analysis. Cancer Prevention Research 3 1451-1461. (doi:10.1158/1940-6207.CAPR-10-0157)

Deng XS, Wang S, Deng A, Liu B, Edgerton SM, Lind SE, Wahdan-Alaswad R \& Thor AD 2012 Metformin targets Stat3 to inhibit cell growth and induce apoptosis in triple-negative breast cancers. Cell Cycle 11 367-376. (doi:10.4161/cc.11.2.18813)

Donadon V, Balbi M, Ghersetti M, Grazioli S, Perciaccante A, Della Valentina G, Gardenal R, Dal Mas M, Casarin P, Zanette G et al. 2009 Antidiabetic therapy and increased risk of hepatocellular carcinoma in chronic liver disease. World Journal of Gastroenterology 15 2506-2511. (doi:10.3748/wjg.15.2506)

Dowling RJ, Zakikhani M, Fantus IG, Pollak M \& Sonenberg N 2007 Metformin inhibits mammalian target of rapamycin-dependent translation initiation in breast cancer cells. Cancer Research 67 10804-10812. (doi:10.1158/0008-5472.CAN-07-2310)

Duggan C, Irwin ML, Xiao L, Henderson KD, Smith AW, Baumgartner RN, Baumgartner KB, Bernstein L, Ballard-Barbash R \& McTiernan A 2011 Associations of insulin resistance and adiponectin with mortality in women with breast cancer. Journal of Clinical Oncology 29 32-39. (doi:10.1200/JCO.2009.26.4473)

El-Mir MY, Nogueira V, Fontaine E, Averet N, Rigoulet M \& Leverve X 2000 Dimethylbiguanide inhibits cell respiration via an indirect effect targeted on the respiratory chain complex I. Journal of Biological Chemistry 275 223-228. (doi:10.1074/jbc.275.1.223)

Emaus A, Veierod MB, Tretli S, Finstad SE, Selmer R, Furberg AS, Bernstein L, Schlichting E \& Thune I 2010 Metabolic profile, physical activity, and mortality in breast cancer patients. Breast Cancer Research and Treatment 121 651-660. (doi:10.1007/s10549009-0603-y)

Erickson K, Patterson RE, Flatt SW, Natarajan L, Parker BA, Heath DD, Laughlin GA, Saquib N, Rock CL \& Pierce JP 2011 Clinically defined type 2 diabetes mellitus and prognosis in early-stage breast cancer. Journal of Clinical Oncology 29 54-60. (doi:10.1200/JCO. 2010.29.3183)

Evans JM, Donnelly LA, Emslie-Smith AM, Alessi DR \& Morris AD 2005 Metformin and reduced risk of cancer in diabetic patients. BMJ330 1304-1305. (doi:10.1136/bmj.38415.708634.F7)

Everhart J \& Wright D 1995 Diabetes mellitus as a risk factor for pancreatic cancer. A meta-analysis. Journal of the American Medical Association 273 1605-1609. (doi:10.1001/jama.1995. 03520440059037)

Foretz M, Hebrard S, Leclerc J, Zarrinpashneh E, Soty M, Mithieux G, Sakamoto K, Andreelli F \& Viollet B 2010 Metformin inhibits hepatic gluconeogenesis in mice independently of the LKB1/AMPK pathway via a decrease in hepatic energy state. Journal of Clinical Investigation 120 2355-2369. (doi:10.1172/ JCI40671)

Goodwin PJ, Ennis M, Pritchard KI, Trudeau ME, Koo J, Madarnas Y, Hartwick W, Hoffman B \& Hood N 2002 Fasting insulin and outcome in early-stage breast cancer: results of a prospective cohort study. Journal of Clinical Oncology 20 42-51. (doi:10.1200/ JCO.20.1.42)

Goodwin PJ, Pritchard KI, Ennis M, Clemons M, Graham M \& Fantus IG 2008 Insulin-lowering effects of metformin in women with early breast cancer. Clinical Breast Cancer 8 501-505. (doi:10.3816/CBC.2008.n.060)

Goodwin PJ, Stambolic V, Lemieux J, Chen BE, Parulekar WR, Gelmon KA, Hershman DL, Hobday TJ, Ligibel JA, Mayer IA et al. 2011 Evaluation of metformin in early breast cancer: a modification of the traditional paradigm for clinical testing of anti-cancer agents. Breast Cancer Research and Treatment 126 215-220. (doi:10.1007/s10549-010-1224-1)

Gwinn DM, Shackelford DB, Egan DF, Mihaylova MM, Mery A, Vasquez DS, Turk BE \& Shaw RJ 2008 AMPK phosphorylation of raptor mediates a metabolic checkpoint. Molecular Cell $\mathbf{3 0}$ 214-226. (doi:10.1016/j.molcel.2008.03.003)

Hadad S, Iwamoto T, Jordan L, Purdie C, Bray S, Baker L, Jellema G, Deharo S, Hardie DG, Pusztai L et al. 2011 Evidence for biological effects of metformin in operable breast cancer: a pre-operative, window-of-opportunity, randomized trial. Breast Cancer Research and Treatment 128 783-794. (doi:10.1007/s10549-011-1612-1)

Hassan MM, Curley SA, Li D, Kaseb A, Davila M, Abdalla EK, Javle M, Moghazy DM, Lozano RD, Abbruzzese JL et al. 2010 Association of diabetes duration and diabetes treatment with the risk of hepatocellular carcinoma. Cancer 116 1938-1946. (doi:10.1002/) cncr.24982) 
Hawley SA, Gadalla AE, Olsen GS \& Hardie DG 2002 The antidiabetic drug metformin activates the AMP-activated protein kinase cascade via an adenine nucleotide-independent mechanism. Diabetes $\mathbf{5 1}$ 2420-2425. (doi:10.2337/diabetes.51.8.2420)

Hirsch HA, Iliopoulos D, Tsichlis PN \& Struhl K 2009 Metformin selectively targets cancer stem cells, and acts together with chemotherapy to block tumor growth and prolong remission. Cancer Research 69 7507-7511. (doi:10.1158/0008-5472.CAN09-2994)

Hosono K, Endo H, Takahashi H, Sugiyama M, Sakai E, Uchiyama T, Suzuki K, Iida H, Sakamoto Y, Yoneda K et al. 2010 Metformin suppresses colorectal aberrant crypt foci in a short-term clinical trial. Cancer Prevention Research 3 1077-1083. (doi:10.1158/19406207.CAPR-10-0186)

Huang X, Wullschleger S, Shpiro N, McGuire VA, Sakamoto K, Woods YL, McBurnie W, Fleming S \& Alessi DR 2008 Important role of the LKB1-AMPK pathway in suppressing tumorigenesis in PTENdeficient mice. Biochemical Journal 412 211-221. (doi:10.1042/ BJ20080557)

Iliopoulos D, Hirsch HA \& Struhl K 2011 Metformin decreases the dose of chemotherapy for prolonging tumor remission in mouse xenografts involving multiple cancer cell types. Cancer Research 71 3196-3201. (doi:10.1158/0008-5472.CAN-10-3471)

Inoki K, Li Y, Xu T \& Guan KL 2003 Rheb GTPase is a direct target of TSC2 GAP activity and regulates mTOR signaling. Genes and Development 17 1829-1834. (doi:10.1101/gad.1110003)

Irwin ML, Duggan C, Wang CY, Smith AW, McTiernan A, Baumgartner RN, Baumgartner KB, Bernstein L \& Ballard-Barbash R 2011 Fasting C-peptide levels and death resulting from all causes and breast cancer: the health, eating, activity, and lifestyle study. Journal of Clinical Oncology 29 47-53. (doi:10.1200/JCO.2010.28.4752)

Isakovic A, Harhaji L, Stevanovic D, Markovic Z, Sumarac-Dumanovic M, Starcevic V, Micic D \& Trajkovic V 2007 Dual antiglioma action of metformin: cell cycle arrest and mitochondria-dependent apoptosis. Cellular and Molecular Life Sciences 64 1290-1302. (doi:10.1007/ s00018-007-7080-4)

Jin HE, Hong SS, Choi MK, Maeng HJ, Kim DD, Chung SJ \& Shim CK 2009 Reduced antidiabetic effect of metformin and downregulation of hepatic Octl in rats with ethynylestradiol-induced cholestasis. Pharmaceutical Research 26 549-559. (doi:10.1007/ s11095-008-9770-5)

Jiralerspong S, Palla SL, Giordano SH, Meric-Bernstam F, Liedtke C, Barnett CM, Hsu L, Hung MC, Hortobagyi GN \& Gonzalez-Angulo AM 2009 Metformin and pathologic complete responses to neoadjuvant chemotherapy in diabetic patients with breast cancer. Journal of Clinical Oncology 27 3297-3302. (doi:10.1200/JCO.2009. 19.6410)

Jones RG, Plas DR, Kubek S, Buzzai M, Mu J, Xu Y, Birnbaum MJ \& Thompson CB 2005 AMP-activated protein kinase induces a p53dependent metabolic checkpoint. Molecular Cell 18 283-293. (doi:10.1016/j.molcel.2005.03.027)

Kahn BB, Alquier T, Carling D \& Hardie DG 2005 AMP-activated protein kinase: ancient energy gauge provides clues to modern understanding of metabolism. Cell Metabolism 1 15-25. (doi:10. 1016/j.cmet.2004.12.003)

Kalender A, Selvaraj A, Kim SY, Gulati P, Brule S, Viollet B, Kemp BE, Bardeesy N, Dennis P, Schlager JJ et al. 2010 Metformin, independent of AMPK, inhibits mTORC1 in a rag GTPasedependent manner. Cell Metabolism 11 390-401. (doi:10.1016/j. cmet.2010.03.014)

Kasper JS \& Giovannucci E 2006 A meta-analysis of diabetes mellitus and the risk of prostate cancer. Cancer Epidemiology, Biomarkers $\mathcal{E}$ Prevention 15 2056-2062. (doi:10.1158/1055-9965.EPI-06-0410)

Kasper JS, Liu Y \& Giovannucci E 2009 Diabetes mellitus and risk of prostate cancer in the health professionals follow-up study. International Journal of Cancer 124 1398-1403. (doi:10.1002/ijc. 24044)
Kendall DM \& Bergenstal RM 2001 Comprehensive management of patients with type 2 diabetes: establishing priorities of care. American Journal of Managed Care 7 S327-S343 (quiz S344-328).

Landman GW, Kleefstra N, van Hateren KJ, Groenier KH, Gans RO \& Bilo HJ 2010 Metformin associated with lower cancer mortality in type 2 diabetes: ZODIAC-16. Diabetes Care 33 322-326. (doi:10.2337/dc09-1380)

Larsson SC \& Wolk A 2011 Diabetes mellitus and incidence of kidney cancer: a meta-analysis of cohort studies. Diabetologia 54 1013-1018. (doi:10.1007/s00125-011-2051-6)

Larsson SC, Orsini N \& Wolk A 2005 Diabetes mellitus and risk of colorectal cancer: a meta-analysis. Journal of the National Cancer Institute 97 1679-1687. (doi:10.1093/jnci/dji375)

Larsson SC, Orsini N, Brismar K \& Wolk A 2006 Diabetes mellitus and risk of bladder cancer: a meta-analysis. Diabetologia 49 2819-2823. (doi:10.1007/s00125-006-0468-0)

Larsson SC, Mantzoros CS \& Wolk A 2007 Diabetes mellitus and risk of breast cancer: a meta-analysis. International Journal of Cancer 121 856-862. (doi:10.1002/ijc.22717)

Lee JW, Soung YH, Kim SY, Lee HW, Park WS, Nam SW, Kim SH, Lee JY, Yoo NJ \& Lee SH 2005 PIK3CA gene is frequently mutated in breast carcinomas and hepatocellular carcinomas. Oncogene 24 1477-1480. (doi:10.1038/sj.onc.1208304)

Lee MS, Hsu CC, Wahlqvist ML, Tsai HN, Chang YH \& Huang YC 2011 Type 2 diabetes increases and metformin reduces total, colorectal, liver and pancreatic cancer incidences in Taiwanese: a representative population prospective cohort study of 800000 individuals. BMC Cancer 11 20. (doi:10.1186/1471-2407-11-20)

Lee JH, Kim TI, Jeon SM, Hong SP, Cheon JH \& Kim WH 2012 The effects of metformin on the survival of colorectal cancer patients with diabetes mellitus. International Journal of Cancer. In press. (doi:10.1002/ijc.26421)

Li D, Yeung SC, Hassan MM, Konopleva M \& Abbruzzese JL 2009 Antidiabetic therapies affect risk of pancreatic cancer. Gastroenterology 137 482-488. (doi:10.1053/j.gastro.2009.04.013)

Libby G, Donnelly LA, Donnan PT, Alessi DR, Morris AD \& Evans JM 2009 New users of metformin are at low risk of incident cancer: a cohort study among people with type 2 diabetes. Diabetes Care 32 1620-1625. (doi:10.2337/dc08-2175)

Liu M, Howes A, Lesperance J, Stallcup WB, Hauser CA, Kadoya K, Oshima RG \& Abraham RT 2005 Antitumor activity of rapamycin in a transgenic mouse model of ErbB2-dependent human breast cancer. Cancer Research 65 5325-5336. (doi:10.1158/0008-5472. CAN-04-4589)

Liu B, Fan Z, Edgerton SM, Deng XS, Alimova IN, Lind SE \& Thor AD 2009 Metformin induces unique biological and molecular responses in triple negative breast cancer cells. Cell Cycle 8 2031-2040. (doi:10.4161/cc.8.13.8814)

Liu B, Fan Z, Edgerton SM, Yang X, Lind SE \& Thor AD 2011 Potent anti-proliferative effects of metformin on trastuzumabresistant breast cancer cells via inhibition of erbB2/IGF-1 receptor interactions. Cell Cycle 10 2959-2966. (doi:10.4161/cc.10. 17.16359)

Long YC \& Zierath JR 2006 AMP-activated protein kinase signaling in metabolic regulation. Journal of Clinical Investigation 116 1776-1783. (doi:10.1172/JCI29044)

Ma J, Li H, Giovannucci E, Mucci L, Qiu W, Nguyen PL, Gaziano JM, Pollak M \& Stampfer MJ 2008 Prediagnostic body-mass index, plasma C-peptide concentration, and prostate cancer-specific mortality in men with prostate cancer: a long-term survival analysis. Lancet Oncology 9 1039-1047. (doi:10.1016/S1470-2045 (08)70235-3)

Mazzone PJ, Rai HS, Beukemann M, Xu M, Abdallah R \& Sasidhar M 2010 The effect of metformin and thiazolidinedione use on lung cancer. Chest 138 (Suppl 882A).

Meiers P, Sharon E, Dong Yu W, Pooni A, McCready D \& Leong W 2010 Significant reduction of triple negative breast cancers in diabetic women on metformin. San Antonio Breast Cancer Symposium, (PD03-01). 
Memmott RM, Mercado JR, Maier CR, Kawabata S, Fox SD \& Dennis PA 2010 Metformin prevents tobacco carcinogen-induced lung tumorigenesis. Cancer Prevention Research 3 1066-1076. (doi:10.1158/1940-6207.CAPR-10-0055)

Mitri J, Castillo J \& Pittas AG 2008 Diabetes and risk of non-Hodgkin's lymphoma: a meta-analysis of observational studies. Diabetes Care 31 2391-2397. (doi:10.2337/dc08-1034)

Monami M, Lamanna C, Balzi D, Marchionni N \& Mannucci E 2009 Sulphonylureas and cancer: a case-control study. Acta Diabetologica 46 279-284. (doi:10.1007/s00592-008-0083-2)

Monami M, Colombi C, Balzi D, Dicembrini I, Giannini S, Melani C, Vitale V, Romano D, Barchielli A, Marchionni N et al. 2011 Metformin and cancer occurrence in insulin-treated type 2 diabetic patients. Diabetes Care 34 129-131. (doi:10.2337/dc10-1287)

Morgensztern D \& McLeod HL 2005 PI3K/Akt/mTOR pathway as a target for cancer therapy. Anti-Cancer Drugs 16 797-803. (doi:10.1097/01.cad.0000173476.67239.3b)

Mulligan AM, O’Malley FP, Ennis M, Fantus IG \& Goodwin PJ 2007 Insulin receptor is an independent predictor of a favorable outcome in early stage breast cancer. Breast Cancer Research and Treatment 106 39-47. (doi:10.1007/s10549-006-9471-x)

Niraula S, Stambolic V, Dowling RJO, Ennis M, Chang MC, Done SJ, Hallak S, Hood N, Leong W, Escallon J, et al. 2010 Clinical and biologic effects of metformin in early stage breast cancer. San Antonio Breast Cancer Symposium, (PD03-06).

Papa V \& Belfiore A 1996 Insulin receptors in breast cancer: biological and clinical role. Journal of Endocrinological Investigation 19 324-333.

Pasanisi P, Berrino F, De Petris M, Venturelli E, Mastroianni A \& Panico S 2006 Metabolic syndrome as a prognostic factor for breast cancer recurrences. International Journal of Cancer 119 236-238. (doi:10.1002/ijc.21812)

Perez-Tenorio G, Alkhori L, Olsson B, Waltersson MA, Nordenskjold B, Rutquist LE, Skoog L \& Stal O 2007 PIK3CA mutations and PTEN loss correlate with similar prognostic factors and are not mutually exclusive in breast cancer. Clinical Cancer Research 13 3577-3584. (doi:10.1158/1078-0432.CCR-06-1609)

Phoenix KN, Vumbaca F \& Claffey KP 2009 Therapeutic metformin/ AMPK activation promotes the angiogenic phenotype in the $\mathrm{ER} \alpha$ negative MDA-MB-435 breast cancer model. Breast Cancer Research and Treatment 113 101-111. (doi:10.1007/s10549-008-9916-5)

Phoenix KN, Vumbaca F, Fox MM, Evans R \& Claffey KP 2010 Dietary energy availability affects primary and metastatic breast cancer and metformin efficacy. Breast Cancer Research and Treatment 123 333-344. (doi:10.1007/s10549-009-0647-z)

Pisani P 2008 Hyper-insulinaemia and cancer, meta-analyses of epidemiological studies. Archives of Physiology and Biochemistry 114 63-70. (doi:10.1080/13813450801954451)

Pollak M 2008 Insulin and insulin-like growth factor signalling in neoplasia. Nature Reviews. Cancer 8 915-928. (doi:10.1038/nrc2536)

Polyak K \& Weinberg RA 2009 Transitions between epithelial and mesenchymal states: acquisition of malignant and stem cell traits. Nature Reviews. Cancer 9 265-273. (doi:10.1038/nrc2620)

Pritchard KI, Shepherd LE, Chapman JA, Norris BD, Cantin J, Goss PE, Dent SF, Walde D, Vandenberg TA, Findlay B et al. 2011 Randomized trial of tamoxifen versus combined tamoxifen and octreotide LAR therapy in the adjuvant treatment of early-stage breast cancer in postmenopausal women: NCICCTG MA.14. Journal of Clinical Oncology 29 3869-3876. (doi:10.1200/JCO.2010.33.7006)

Sansal I \& Sellers WR 2004 The biology and clinical relevance of the PTEN tumor suppressor pathway. Journal of Clinical Oncology 22 2954-2963. (doi:10.1200/JCO.2004.02.141)
Shaw RJ, Bardeesy N, Manning BD, Lopez L, Kosmatka M, De Pinho RA \& Cantley LC 2004 The LKB1 tumor suppressor negatively regulates mTOR signaling. Cancer Cell 6 91-99. (doi:10.1016/j.ccr.2004.06.007)

Shaw RJ, Lamia KA, Vasquez D, Koo SH, Bardeesy N, Depinho RA, Montminy M \& Cantley LC 2005 The kinase LKB1 mediates glucose homeostasis in liver and therapeutic effects of metformin. Science 310 1642-1646. (doi:10.1126/science.1120781)

Shu Y, Sheardown SA, Brown C, Owen RP, Zhang S, Castro RA, Ianculescu AG, Yue L, Lo JC, Burchard EG et al. 2007 Effect of genetic variation in the organic cation transporter 1 (OCT1) on metformin action. Journal of Clinical Investigation 117 1422-1431. (doi:10.1172/JCI30558)

Stambolic V, Woodgett JR, Fantus IG, Pritchard KI \& Goodwin PJ 2009 Utility of metformin in breast cancer treatment, is neoangiogenesis a risk factor? Breast Cancer Research and Treatment 114 387-389. (doi:10.1007/s10549-008-0015-4)

Tan BX, Yao WX, Ge J, Peng XC, Du XB, Zhang R, Yao B, Xie K, Li LH, Dong $\mathrm{H}$ et al. 2011 Prognostic influence of metformin as first-line chemotherapy for advanced nonsmall cell lung cancer in patients with type 2 diabetes. Cancer 117 5103-5111. (doi:10.1002/cncr. 26151)

Tomimoto A, Endo H, Sugiyama M, Fujisawa T, Hosono K, Takahashi H, Nakajima N, Nagashima Y, Wada K, Nakagama H et al. 2008 Metformin suppresses intestinal polyp growth in ApcMin/+ mice. Cancer Science 99 2136-2141. (doi:10.1111/j.1349-7006.2008.00933.x)

Tzvetkov MV, Vormfelde SV, Balen D, Meineke I, Schmidt T, Sehrt D, Sabolic I, Koepsell H \& Brockmoller J 2009 The effects of genetic polymorphisms in the organic cation transporters OCT1, OCT2, and OCT3 on the renal clearance of metformin. Clinical Pharmacology and Therapeutics 86 299-306. (doi:10.1038/clpt.2009.92)

Vazquez-Martin A, Oliveras-Ferraros C \& Menendez JA 2009 The antidiabetic drug metformin suppresses HER2 (erbB-2) oncoprotein overexpression via inhibition of the mTOR effector p70S6K1 in human breast carcinoma cells. Cell Cycle 8 88-96. (doi:10.4161/cc.8. $1.7499)$

Wright JL \& Stanford JL 2009 Metformin use and prostate cancer in Caucasian men: results from a population-based case-control study. Cancer Causes $\mathcal{E}$ Control 20 1617-1622. (doi:10.1007/s10552-009$9407-\mathrm{y})$

Yu D \& Hung MC 2000 Overexpression of ErbB2 in cancer and ErbB2targeting strategies. Oncogene 19 6115-6121. (doi:10.1038/sj.onc. 1203972)

Zakikhani M, Dowling R, Fantus IG, Sonenberg N \& Pollak M 2006 Metformin is an AMP kinase-dependent growth inhibitor for breast cancer cells. Cancer Research 66 10269-10273. (doi:10.1158/00085472.CAN-06-1500)

Zhou X, Tan M, Stone Hawthorne V, Klos KS, Lan KH, Yang Y, Yang W, Smith TL, Shi D \& Yu D 2004 Activation of the Akt/mammalian target of rapamycin/4E-BP1 pathway by ErbB2 overexpression predicts tumor progression in breast cancers. Clinical Cancer Research 10 6779-6788. (doi:10.1158/1078-0432.CCR-04-0112)

Zhuang Y \& Miskimins WK 2008 Cell cycle arrest in metformin treated breast cancer cells involves activation of AMPK, downregulation of cyclin D1, and requires p27Kip1 or p21Cip1. Journal of Molecular Signaling 3 18. (doi:10.1186/1750-2187-3-18)

Received in final form 16 February 2012

Accepted 20 February 2012

Made available online as an Accepted Preprint 20 February 2012 